\title{
ASSESSMENT OF PERINATAL OUTCOME AFTER USING NIFEDIPINE VERSUS PLACEBO IN THE TREATMENT OF PRETERM PRELABOR RUPTURE OF MEMBRANES
}

\section{(Randomized controlled study)}

\author{
By
Mohamed Gamal El-Din Ahmed Shafey, Farid Ibrahim Hassan, Mofeed Fawzy Mohamed and Dalia Moneer El-Lahouny* \\ Department of Obstetrics and Gynecology, Faculty of Medicine, Al-Azhar University \\ Department of Pediatrics*, Faculty of Medicine, Al-Menoufia University \\ Corresponding author: Mohamed Gamal El-Din Ahmed Shafey, \\ E-mail: gamalshafey66@gmail.com
}

\begin{abstract}
Background: Preterm birth is the most common cause of neonatal morbidity and mortality worldwide and accounts for approximately $75 \%$ of all neonatal deaths and $50 \%$ of childhood neurological morbidities. Around one-third of preterm deliveries start with preterm pre-labor rupture of membranes (PPROM).

Objective: To assess the value of Nifedipine to change the perinatal outcome in cases of preterm pre-labor rupture of membranes.

Patients and methods: This was a randomized, controlled study that included and followed 200 pregnant women. One hundred pregnant women were recruited in the Nifedipine group in addition to 100 pregnant women were recruited as a control group from Obstetric Department of Shebin El Kom Teaching Hospital during the period form to 2017-2019.
\end{abstract}

Results: In this randomized clinical trial among women with PPROM without contractions, we found no significant differences between treatment with nifedipine or placebo in terms of perinatal outcomes and prolongation of pregnancy.

Conclusion: On perinatal outcomes or prolongation of pregnancy in women with PPROM without contractions.

Keywords: Nifedipine versus placebo, preterm prelabor rupture of membranes.

\section{INTRODUCTION}

Despite the high 25 prevalence of preterm birth following PPROM, the optimal management of PPROM remains a topic of debate and is hindered by a lack of evidence. After rupture of the membranes, there is a high risk that labor will follow within days. Most women with PPROM who receive conservative management deliver within one week. Most clinical guidelines advise to administer a $48 \mathrm{~h}$ course of corticosteroids and transfer to a tertiary care center to improve neonatal outcome (Flenady et al., 2014). One mechanism by which tocolysis 
might improve outcome is to delay delivery during this $48 \mathrm{~h}$ period. However, the use of tocolysis in this period, but especially after $48 \mathrm{~h}$, is subject to debate. The prevalence of adverse neonatal outcome is strongly related to gestational age at delivery declining from $77 \%$ at 24 to 27 weeks to less than $2 \%$ from 34 weeks onwards (De Heus et al., 2011).

Administration of tocolytic drugs after the $48 \mathrm{~h}$ period may further increase the latency period and thereby improve gestational age at delivery. However, prolongation of pregnancy in PPROM does not automatically lead to an improvement of neonatal outcome. As infection is detected in a major part of all women with PPROM, prolongation of pregnancy may result in longer exposure of the fetus to a harmful infective environment. Therefore, the benefit of postponing delivery must be weighed against the potential harm of the increased risk on maternal and perinatal infection. A recent Cochrane review indicated that, when compared to placebo, tocolysis in PPROM is associated with an average 73 $\mathrm{h}$ longer latency of delivery and fewer births within $48 \mathrm{~h}$. However, tocolysis was also associated with an increased risk of a 5 min Apgar score under 7 and an increased need for ventilation support. Different tocolytic drugs were compared, mostly betamimetics (ritodrine). Tocolysis significantly increased the duration of pregnancy without any significant effects on maternal and neonatal outcomes. Women with PPROM before 34 weeks of gestation tocolysis increased the rate of chorioamnionitis, neonatal outcome was comparable (Jobe and Bancalari, 2010).
The aim of the study was to assess the value of Nifedipine to change the perinatal outcome in cases of preterm prelabor rupture of membranes.

\section{PATIENTS AND METHODS}

This randomized, controlled, study included and followed 200 pregnant women. 100 pregnant women were recruited in the Nifedipine group in addition to 100 pregnant women were recruited as a control group from Obstetric Department of Shebin El Kom Teaching Hospital during the period form to 20172019.

A written informed consent was obtained from every eligible woman. Women were informed about the study objectives, methodology, risk, and benefit. The study's protocol was reviewed and approved by IRB, ethics committee or Audit Department of Obstetrics and Gynecology, Shebin El Kom Teaching Hospital.

Inclusion Criteria: Pregnant women during aged $20-30$ years, patients accepted to join the study after signing informed consent, women with gestational age between 28 and 37 weeks, recent onset of rupture of membranes within $24 \mathrm{~h}$, ruptured membranes without signs of active labor and ruptured membranes without signs of infection.

Exclusion Criteria: $\geq 3$ contractions per $10 \mathrm{~min}$ (signs of active labor), previous treatment with tocolysis in the last 7 days (tocolysis for $<6 \mathrm{~h}$ for transportation was allowed), ruptured membranes $\geq 72 \mathrm{~h}$, signs of chorioamnionitis or intra uterine infection, signs of fetal distress, fetal major congenital anomaly, contraindication for the use of nifedipine, 
maternal disease as reason 92 for delivery (such as hypertension, HELLP syndrome or preeclampsia) and patient who refuse to take part in the study.

To detect a reduction in adverse perinatal outcome from $30 \%$ in the placebo group to $10 \%$ in the nifedipine group, 200 women (100 per group) were needed (two-sided test, type I error $=0.05$, power $=80 \%)$.

Baseline characteristics of the included patients: Baseline demographics of the patient entered in a web-based database. We collected Gestational age at study entry, maternal age, body mass index, smoking status, nulliparity, prior preterm birth, twin gestation, laboratory results at entry, prophylactic antibiotic therapy and corticosteroid administration.

Study medication consisted of one tablet every six hours, administered orally (containing $20 \mathrm{mg}$ nifedipine slow release or placebo). The medication was given until the start of active labor (>3 contractions per $30 \mathrm{~min}$ ), with a maximum of 18 days or until gestational age of $34+0$ weeks. The length of the therapy was limited to 18 days, based on the assumption that prolongation of pregnancy of more than two weeks, if clinically relevant, should show an effect on perinatal outcome. The medication package was stored by the patient, and the administration of the study medication was noted in her medical record. Antenatal corticosteroids were administered according to national guidelines, advising antenatal corticosteroids to women in preterm labor $<34$ weeks of gestation. Prophylactic antibiotic therapy and magnesium sulphate were administered according to local protocol, as was maternal 121 and fetal monitoring.

Laboratory investigations were done in the form of leukocytes and CRP.

\section{Statistical Analysis:}

An Excel spreadsheet was established for the entry of data. We used validation checks on numerical variables and optionbased data entry method for categorical variables to reduce potential errors. The analyses were carried with SPSS software (Statistical Package for the Social Sciences, version 24, SSPS Inc, Chicago, IL, USA). Frequency tables with percentages were used for categorical variables and descriptive statistics (median and interquartile range [IQR]) were used for numerical variables. Independent Student t-test or MannWhitney test were used to compare quantitative variables, while Chi-square test or was used to analyze categorical variables. The main outcome variable, adverse perinatal outcome and secondary neonatal outcomes were assessed by calculating rates in the two groups, relative risks and $95 \%$ confidence interval. A p-value $<0.05$ is considered statistically significant. 


\section{RESULTS}

The mean gestational age was 33.6 $( \pm 2.48)$ in Nifedipine group and 33.4 $( \pm 2.52)$ in placebo group. The mean maternal age was 27.1 $( \pm 5.73)$ in Nifedipine group and $25.6( \pm 5.52)$ in placebo group. Mean body mass index is 25.8 (2.2) in Nifedipine group and 24.1 (1.5) in placebo group. The mean parity was $0.89(0.76)$ in nifedipine group and $0.70(0.79)$ in placebo group. Only $1.0 \%$ of the participants were smoker in nifedipine group and no smoker in the control group. Only $6.0 \%$ of the participants experienced prior preterm birth in nifedipine group and $5.0 \%$ of the participants experienced prior preterm birth in control group. Only $3.0 \%$ of the participants reported twin gestation in nifedipine group and $3.0 \%$ of the participants reported twin gestation in control group. There were no statistically significant differences between nifedipine group and control group regarding gestational age, maternal age, body mass index, parity, smoking, prior preterm birth, and twin gestation ( $\mathrm{p}$ value $>0.05$ ) (Table 1).

Table (1): Baseline characteristics of the study cohort

\begin{tabular}{|c|c|c|c|c|c|c|}
\hline \multirow{2}{*}{\multicolumn{2}{|c|}{ Parameters }} & \multicolumn{2}{|c|}{$\begin{array}{c}\text { Nifedipine } \\
(\mathbf{n}=100)\end{array}$} & \multicolumn{2}{|c|}{$\begin{array}{c}\text { Placebo } \\
(n=100)\end{array}$} & \multirow{2}{*}{$\begin{array}{c}\mathrm{P}- \\
\text { value }\end{array}$} \\
\hline & & Mean & SD & Mean & SD & \\
\hline \multicolumn{2}{|l|}{ Gestational age } & 33.6 & 2.48 & 33.4 & 2.52 & $>0.05$ \\
\hline \multicolumn{2}{|l|}{ Maternal age } & 27.1 & 5.73 & 25.6 & 5.85 & $>0.05$ \\
\hline \multicolumn{2}{|l|}{ Body mass index } & 25.8 & 2.2 & 24.1 & 1.5 & $<0.001$ \\
\hline \multicolumn{2}{|l|}{ Parity } & 0.89 & 0.76 & 0.70 & 0.79 & 0.241 \\
\hline & & $\mathbf{N}$ & $\%$ & $\mathbf{N}$ & $\%$ & \\
\hline \multirow{2}{*}{ Smoking } & Yes & 1 & $1.0 \%$ & 0 & $0.0 \%$ & \multirow{2}{*}{$>0.05$} \\
\hline & No & 99 & $99.0 \%$ & 100 & $100.0 \%$ & \\
\hline \multirow{2}{*}{$\begin{array}{l}\text { Prior preterm } \\
\text { birth }\end{array}$} & Yes & 6 & $6.0 \%$ & 5 & $5.0 \%$ & \multirow{2}{*}{$>0.05$} \\
\hline & No & 94 & $94.0 \%$ & 95 & $95.0 \%$ & \\
\hline \multirow{2}{*}{ Twin gestation } & Yes & 3 & $3.0 \%$ & 2 & $2.0 \%$ & \multirow{2}{*}{$>0.05$} \\
\hline & No & 97 & $97.0 \%$ & 98 & $98.0 \%$ & \\
\hline
\end{tabular}

Median leukocytic count was 11.2 in nifedipine group and 12.1 in control group. Median CRP count was 5.0 in nifedipine group and 7.0 in control group. Prophylactic antibiotic therapy was reported in $16.0 \%$ of the participants of nifedipine group and placebo group. Corticosteroid administration was reported in $30.0 \%$ of the participants of nifedipine group and $25.0 \%$ of the participants in placebo group. There were no statistically significant differences between nifedipine group and control group regarding leukocytes, CRP, prophylactic antibiotic therapy, and corticosteroid administration ( $p$ value> 0.05) (Table 2). 
Table (2): Laboratory and treatment data of the study cohort

\begin{tabular}{|c|c|c|c|c|c|c|}
\hline \multirow{2}{*}{ Groups } & \multicolumn{2}{c|}{$\begin{array}{c}\text { Nifedipine } \\
\text { (n=100) }\end{array}$} & \multicolumn{2}{c|}{$\begin{array}{c}\text { Placebo } \\
\text { (n=100) }\end{array}$} & \multirow{2}{*}{ P value } \\
\cline { 3 - 6 } & & Median & IQR & Median & IQR & \\
\hline \multicolumn{2}{|c|}{ Leukocytes } & 11.2 & $9.4-12.5$ & 12.1 & $9.5-13.1$ & $>0.05$ \\
\hline \multicolumn{2}{|c|}{ CRP } & 5.0 & $3.0-6.0$ & 7.0 & $3.0-11.0$ & $>0.05$ \\
\hline \multirow{2}{*}{$\begin{array}{c}\text { Prophylactic } \\
\text { antibiotic therapy }\end{array}$} & & $\mathbf{N}$ & $\mathbf{\%}$ & $\mathbf{N}$ & $\mathbf{\%}$ & \\
\cline { 2 - 6 } & Yes & 16 & $16.0 \%$ & 16 & $16.0 \%$ & \multirow{2}{*}{$>0.05$} \\
\cline { 2 - 6 } $\begin{array}{c}\text { Corticosteroids } \\
\text { administered }\end{array}$ & No & 84 & $84.0 \%$ & 84 & $84.0 \%$ & \\
\cline { 2 - 6 } & No & 30 & $30.0 \%$ & 25 & $25.0 \%$ & \multirow{2}{*}{$>0.05$} \\
\hline
\end{tabular}

Perinatal mortality was reported in $2.0 \%$ of the participants of nifedipine group and $3.0 \%$ of the participants in placebo group. Broncho pulmonary dysplasia was reported in $0.0 \%$ of the participants of nifedipine group and 6.0\% of the participants in placebo group. PVL $>$ grade I was reported in $1.0 \%$ of the participants of nifedipine group and $2.0 \%$ of the participants in placebo group. IVH $>$ grade II was reported in $2.0 \%$ of the participants of nifedipine group and $2.0 \%$ of the participants in placebo group. NEC $>$ grade I was reported in $2.0 \%$ of the participants of nifedipine group and $5.0 \%$ of the participants in placebo group. Culture proven sepsis was reported in $10.0 \%$ of the participants of nifedipine group and $15.0 \%$ of the participants in placebo group. There were no statistically significant differences between nifedipine group and control group regarding perinatal mortality, $\mathrm{PVL}>$ grade $\mathrm{I}, \mathrm{IVH}>$ grade II, and corticosteroid administration, NEC > grade I, and culture proven sepsis ( $p$ value> 0.05). However, broncho pulmonary dysplasia was significantly higher in placebo group than nifedipine group $(\mathrm{p}$ value $=0.021)($ Table 3$)$.

Table (3): Primary and secondary outcomes of our study

\begin{tabular}{|c|c|c|c|c|c|c|}
\hline \multirow{2}{*}{\multicolumn{2}{|c|}{ Parameters }} & \multicolumn{2}{|c|}{$\begin{array}{l}\text { Nifedipine } \\
(\mathbf{n}=\mathbf{1 0 0})\end{array}$} & \multicolumn{2}{|c|}{$\begin{array}{l}\text { Placebo } \\
(n=100)\end{array}$} & \multirow{2}{*}{$\begin{array}{c}\mathbf{P} \\
\text { value }\end{array}$} \\
\hline & & $\mathbf{N}$ & $\%$ & $\mathbf{N}$ & $\%$ & \\
\hline \multirow{2}{*}{ Perinatal mortality } & Yes & 2 & $2.0 \%$ & 3 & $3.0 \%$ & \multirow{2}{*}{$>0.05$} \\
\hline & No & 98 & $98.0 \%$ & 97 & $97.0 \%$ & \\
\hline \multirow{2}{*}{$\begin{array}{l}\text { Broncho } \\
\text { pulmonary } \\
\text { dysplasia }\end{array}$} & Yes & 0 & $0.0 \%$ & 6 & $0.0 \%$ & \multirow[b]{2}{*}{0.021} \\
\hline & No & 100 & $100.0 \%$ & 94 & $94.0 \%$ & \\
\hline \multirow{2}{*}{ PVL $>$ grade I } & Yes & 1 & $1.0 \%$ & 2 & $2.0 \%$ & \multirow{2}{*}{$>0.05$} \\
\hline & No & 99 & $99.0 \%$ & 98 & $98.0 \%$ & \\
\hline \multirow{2}{*}{$\mathrm{IVH}>$ grade II } & Yes & 2 & $2.0 \%$ & 2 & $2.0 \%$ & \multirow{2}{*}{$>0.05$} \\
\hline & No & 98 & $98.0 \%$ & 98 & $98.0 \%$ & \\
\hline \multirow{2}{*}{ NEC $>$ grade I } & Yes & 2 & $5.0 \%$ & 5 & $5.0 \%$ & \multirow{2}{*}{$>0.05$} \\
\hline & No & 95 & $95.0 \%$ & 95 & $95.0 \%$ & \\
\hline \multirow{2}{*}{$\begin{array}{c}\text { Culture proven } \\
\text { sepsis }\end{array}$} & Yes & 10 & $10.0 \%$ & 15 & $15.0 \%$ & \multirow{2}{*}{$>0.05$} \\
\hline & No & 90 & $90.0 \%$ & 85 & $85.0 \%$ & \\
\hline
\end{tabular}


Mean birth weight was 1810 in nifedipine group and 1524 in control group. NICU admittance was found in $20.0 \%$ of the participants of nifedipine group and $23 \%$ in placebo group. Median NICU Length was 11.0 in nifedipine group and 20.0 in control group. Ventilatory support was found in $5.0 \%$ of the participants of nifedipine group and
$6 \%$ in placebo group. Median ventilatory support length was 1.0 in nifedipine group and 4.0 in control group. There were no statistically significant different between nifedipine group and control group regarding birth weight, NICU admittance, NICU length, ventilation support, and ventilation support length ( $\mathrm{p}$ value> 0.05 ) (Table 4).

Table (4): Secondary outcomes on the child level

\begin{tabular}{|c|c|c|c|c|c|c|}
\hline \multirow{2}{*}{\multicolumn{2}{|c|}{ Parameters Groups }} & \multicolumn{2}{|c|}{$\begin{array}{c}\text { Nifedipine } \\
(\mathbf{n}=100)\end{array}$} & \multicolumn{2}{|c|}{$\begin{array}{l}\text { Placebo } \\
(n=100)\end{array}$} & \multirow{2}{*}{$\begin{array}{c}\mathbf{P} \\
\text { value }\end{array}$} \\
\hline & & Mean & SD & Mean & SD & \\
\hline \multicolumn{2}{|c|}{ Birth weight (g) } & 1810 & 210 & 1524 & 240 & \multirow{2}{*}{$<0.001$} \\
\hline \multirow{3}{*}{$\begin{array}{c}\text { NICU } \\
\text { admittance }\end{array}$} & & $\mathrm{N}$ & $\%$ & $\mathrm{~N}$ & $\%$ & \\
\hline & Yes & 20 & $20.0 \%$ & 23 & $23.0 \%$ & \multirow{2}{*}{$>0.05$} \\
\hline & No & 80 & $80.0 \%$ & 23 & $23.0 \%$ & \\
\hline \multirow{2}{*}{\multicolumn{2}{|c|}{ NICU Length (days) }} & Median & IQR & Median & IQR & \multirow{2}{*}{$>0.05$} \\
\hline & & 11 & $3-22$ & 20 & $5-55$ & \\
\hline \multirow{3}{*}{$\begin{array}{l}\text { Ventilation } \\
\text { support }\end{array}$} & & $\mathrm{N}$ & $\%$ & $\mathrm{~N}$ & $\%$ & \multirow{3}{*}{$>0.05$} \\
\hline & Yes & 5 & $5.0 \%$ & 6 & $6.0 \%$ & \\
\hline & No & 95 & $95.0 \%$ & 6 & $94.0 \%$ & \\
\hline \multirow{2}{*}{\multicolumn{2}{|c|}{$\begin{array}{l}\text { Ventilation support } \\
\text { length (days) }\end{array}$}} & Median & IQR & Median & IQR & \multirow{2}{*}{$>0.05$} \\
\hline & & 1 & $1-9$ & 4 & $1-8$ & \\
\hline
\end{tabular}

Median gestational age at delivery was 32.0 in nifedipine group and 30.0 in control group. Median length of prolongation of pregnancy at delivery was 11.0 in nifedipine group and 8.0 in control group. Prolongation of pregnancy $\geq 48 \mathrm{~h}$ was reported in $23.0 \%$ of the participants of nifedipine group and $25.0 \%$ of the participants in placebo group. Prolongation of pregnancy $\geq 7$ days was reported in $16.0 \%$ of the participants of nifedipine group and $15.0 \%$ of the participants in placebo group. There was no maternal mortality reported in both groups. Discontinuation of study medication was reported in $19.0 \%$ of the participants of nifedipine group and $18.0 \%$ of the participants in placebo group. Discontinuation of due to progression into labor was reported in $15.0 \%$ of the participants of nifedipine group and $14.0 \%$ of the participants in placebo group. Discontinuation due to side effects was reported in $2.0 \%$ of the participants of nifedipine group and $0.0 \%$ of the participants in placebo group. Discontinuation due to signs of intra uterine infection was reported in $6.0 \%$ of the participants of nifedipine group and $8.0 \%$ of the participants in placebo group. There were no statistically significant difference between nifedipine group and control group regarding gestational age at delivery, prolongation of pregnancy, prolongation of pregnancy $\geq 48 \mathrm{~h}$, prolongation of pregnancy $\geq 7$ days, maternal mortality, discontinuation of study medication, discontinuation of due to progression into labor, discontinuation due to side effects, and discontinuation due to signs of intra uterine infection ( $p$ value > 0.05) (Table 5). 
Table (5): Secondary outcomes on the maternal level

\begin{tabular}{|c|c|c|c|c|c|c|}
\hline \multirow{2}{*}{\multicolumn{2}{|c|}{$\mathrm{P}_{\text {Parameters }}^{\text {Groups }}$}} & \multicolumn{2}{|c|}{$\begin{array}{c}\text { Nifedipine } \\
(\mathrm{n}=100)\end{array}$} & \multicolumn{2}{|c|}{$\begin{array}{l}\text { Placebo } \\
(\mathbf{n}=100)\end{array}$} & \multirow[t]{2}{*}{$P$ value } \\
\hline & & Median & IQR & Median & IQR & \\
\hline \multicolumn{2}{|c|}{$\begin{array}{l}\text { Gestational age at delivery, } \\
\text { weeks }\end{array}$} & \multicolumn{2}{|c|}{$32.0(29.1-33.3)$} & \multicolumn{2}{|c|}{$30.0(26.3-32.1)$} & $>0.05$ \\
\hline \multicolumn{2}{|c|}{$\begin{array}{c}\text { Prolongation of pregnancy, } \\
\text { days }\end{array}$} & \multicolumn{2}{|c|}{$11(7-19)$} & \multicolumn{2}{|c|}{$8(5-25)$} & $>0.05$ \\
\hline \multirow{3}{*}{$\begin{array}{l}\text { Prolongation of } \\
\text { pregnancy } \geq 48 \mathrm{~h}\end{array}$} & & $\mathrm{~N}$ & $\%$ & $\mathrm{~N}$ & $\%$ & \multirow{3}{*}{$>0.05$} \\
\hline & Yes & 23 & $23.0 \%$ & 25 & $25.0 \%$ & \\
\hline & No & 77 & $77.0 \%$ & 75 & $75.0 \%$ & \\
\hline \multirow{2}{*}{$\begin{array}{c}\text { Prolongation of } \\
\text { pregnancy } \geq 7 \text { days }\end{array}$} & Yes & 16 & $16.0 \%$ & 15 & $15.0 \%$ & \multirow{2}{*}{$>0.05$} \\
\hline & No & 84 & $84.0 \%$ & 85 & $85.0 \%$ & \\
\hline \multirow{2}{*}{ Maternal mortality } & Yes & 0 & $0.0 \%$ & 0 & $0.0 \%$ & \multirow{2}{*}{$>0.05$} \\
\hline & No & 100 & $100.0 \%$ & 100 & $100.0 \%$ & \\
\hline \multirow{2}{*}{$\begin{array}{l}\text { Discontinuation of } \\
\text { study medication }\end{array}$} & Yes & 19 & $19.0 \%$ & 18 & $18.0 \%$ & \multirow{2}{*}{$>0.05$} \\
\hline & No & 81 & $81.0 \%$ & 82 & $82.0 \%$ & \\
\hline \multirow{2}{*}{$\begin{array}{l}\text { Discontinuation of } \\
\text { due to progression } \\
\text { into labor }\end{array}$} & Yes & 15 & $15.0 \%$ & 14 & $14.0 \%$ & \multirow{2}{*}{$>0.05$} \\
\hline & No & 85 & $85.0 \%$ & 86 & $86.0 \%$ & \\
\hline \multirow{2}{*}{$\begin{array}{l}\text { Discontinuation due } \\
\text { to side effects }\end{array}$} & Yes & 2 & $2.0 \%$ & 0 & $0.0 \%$ & \multirow{2}{*}{$>0.05$} \\
\hline & No & 98 & $98.0 \%$ & 0 & $100.0 \%$ & \\
\hline \multirow{2}{*}{$\begin{array}{l}\text { Discontinuation due } \\
\text { to signs of intra } \\
\text { uterine infection }\end{array}$} & Yes & 2 & $2.0 \%$ & 4 & $4.0 \%$ & \multirow[b]{2}{*}{$>0.05$} \\
\hline & No & 98 & $98.0 \%$ & 96 & $96.0 \%$ & \\
\hline
\end{tabular}

\section{DISCUSSION}

In this randomized clinical trial among women with PPROM without contractions, we found no significant differences between treatment with nifedipine or placebo in terms of perinatal outcomes and prolongation of pregnancy. Our results were in line with previous studies in which women with PPROM did not seem to benefit from treatment with prolonged tocolysis (Jobe and Bancalari, 2014).

Although we found a comparable rate of composite adverse perinatal outcome, our small sample size indicated that we might have missed a relevant difference. Therefore, it may still be possible that use of nifedipine resulted in a clinically relevant difference in perinatal outcomes in women with PPROM without contractions.

Results of a Cochrane review showed no improvement in neonatal outcomes. Not all trials used standard corticosteroid therapy and antibiotics.

They found that $\mathrm{CCBs}$, specifically nifedipine, is better than no tocolytics for postponing preterm birth for 48 hours, which may help improve outcomes for babies. Compared with betamimetics, CCBs were more effective at postponing birth, had fewer side effects for women, and appeared to improve some important short-term outcomes for the baby (breathing difficulties, gut infections, and admission to special care units). 
Calcium channel blockers were better than other types of tocolytics for some outcomes only. Oxytocin receptor antagonists (ORAs) appear to have fewer side effects for women than CCBs, but ORAs are not as good at reducing preterm birth. Another type of CCB, nicardipine, was only used in three trials, but was not more effective than other tocolytics. Longer-term infant and childhood outcomes were not able to be assessed due to lack of available information. In general, CCBs are more effective than betamimetics, but only sometimes more effective than other types of tocolytics (Mackeen et al., 2014).

In otherwise symptom free women with PPROM is that we found no effect from nifedipine on time to delivery. Furthermore, the number of women that discontinued study medication because of progression into labor was high, and comparable between the groups $(19 \%$ in the nifedipine group versus $18 \%$ in the placebo group).

In absence of such an effect on duration of pregnancy, it is unlikely that children born from women with PPROM will benefit directly from nifedipine. This is in line with our previous study on prolonged tocolysis in women with arrested preterm labor, the APOSTEL II study, that did not show a difference in short term perinatal outcome or at 2-year follow-up.

Roos et al. (2016) women with threatened preterm labor between 26 weeks (plus 0 days) and 32 weeks (plus 2 days) gestation, who had not delivered after 48 hours of tocolysis and a completed course of corticosteroids, were enrolled. Surviving infants were followed up until 6 months after birth.

Analyses completed on an intention-totreat basis. Age at randomization was 29.2 (1.7) weeks for both groups. They concluded that, in patients with threatened preterm labor, nifedipine-maintained tocolysis did not result in a statistically significant reduction in adverse perinatal outcomes when compared with placebo (Nijman et al., 2016).

Although the lower than anticipated rate of adverse perinatal outcomes in the control group indicated that a benefit of nifedipine cannot completely be excluded, its use for maintenance tocolysis did not appear beneficial at this time. Nijman et al. (2016), it was a nationwide multicentre randomized placebo controlled trial. We included women with PPROM without contractions between $24+0$ and $33+6$ weeks of gestation. Participants were randomly allocated to daily $80 \mathrm{mg}$ nifedipine or placebo, until the start of labor, with a maximum of 18 days.

The primary outcome measure was a composite of poor neonatal outcome, including perinatal death, bronchopulmonary dysplasia, periventricular leukomalacia > grade 1, intraventricular hemorrhage > grade 2, necrotizing enterocolitis > stage 1 and culture proven sepsis. Secondary outcomes were gestational age at delivery and prolongation of pregnancy (Roos et al., 2013).

Analysis was by intention to treat. To detect a reduction of poor neonatal outcome from $30 \%$ to $10 \%, 120$ women needed to be randomized. The median gestational age at randomization was 29.9 weeks (IQR 27.7-31.3) in the nifedipine 
group and 27.0 weeks (IQR 24.7-29.9) in the placebo group (Roos et al., 2013).

Other baseline characteristics were comparable. The adverse perinatal outcome occurred in neonates $(33.3 \%)$ in the nifedipine group and $32.1 \%$ in the placebo group. Two perinatal deaths occurred, both in the nifedipine group. Bronchopulmonary dysplasia was seen less frequently in the nifedipine group. Prolongation of pregnancy did not differ between the nifedipine and placebo group. They concluded that randomized trial did not show a beneficial effect of prolonged tocolysis on neonatal (Roos et al., 2013).

No deaths occurred in the nifedipine group and no causal relation could be determined between death and possible side effects of nifedipine. We cannot exclude an indirect effect. It may be hypothesized that the administration of nifedipine in pregnant women has an adverse effect on the fetus, for example by lowering maternal blood pressure and reducing placental perfusion. However, previous studies have shown contradictory results, thus no final conclusions can be drawn (Roos et al., 2013).

Primary outcome measures were the effects on fetal heart rate (FHR) and its variation. Secondary endpoints were the effects on fetal movement and blood flow (pulsatility index - PI) of the umbilical (UA) and medial cerebral arteries. Onehour recordings of FHR and fetal movements were made on each of five successive days (days 0-4). Fetal blood flow velocity patterns were studied daily by Doppler ultrasound. Baseline characteristics of 31 women who had not delivered at day 0 and needed no escape tocolysis did not differ between the study groups. Multilevel analysis showed no significant effect of either tocolytic on FHR and movement parameters over the 5-day study period. The use of tocolytics also did not significantly alter the time courses of PI-values for UA and MCA. This study demonstrated for the first time the direct effects of atosiban on fetal movement, heart rate and blood flow. Tocolysis with either atosiban or nifedipine combined with betamethasone administration appears to have no direct fetal adverse effects (Ugwumadu, 2011).

Looking at separate components, we found a significantly lower rate of bronchopulmonary dysplasia in women treated with nifedipine $(0 \%$ in the nifedipine group compared to $6 \%$ in the placebo group). A possible explanation for this difference could be the higher gestational age at study entry and delivery in the nifedipine group, since the occurrence of bronchopulmonary dysplasia decreases with increasing gestational age at delivery (Weijerman et al., 2010).

All cases of bronchopulmonary dysplasia occurred in neonates born before 30 weeks of gestation. bronchopulmonary dysplasia can only be diagnosed if survival occurs to a corrected age of 36 weeks of gestation.

\section{CONCLUSION}

No beneficial effect of prolonged tocolysis with nifedipine on perinatal outcomes or prolongation of pregnancy in women with PPROM without contractions.

\section{REFERENCES}

1. De Heus R, Mulder E, Derks JB and Visser H. (2011): The effects of the tocolytics 


\section{MOHAMED G. A. SHAFEY et al.,}

atosiban and nifedipine on fetal movements, heart rate and blood flow. Journal of Maternal-Fetal and Neonatal Medicine, 22: 485-490.

2. Flenady V, Wojcieszek AM, Papatsonis DN, Stock OM, Murray L, Jardine LA and Carbonne B. (2014): Calcium channel blockers for inhibiting preterm labour and birth'. Cochrane Database Syst Rev., 2014(6):CD002255.

3. Jobe AH and Bancalari E. (2010): Bronchopulmonary dysplasia. American Journal of Respiratory and Critical Care Medicine, 163(7):1723-1729.

4. Mackeen AD, Seibel-Seamon J, Muhammad J, Baxter JK and Berghella V. (2014): Tocolytics for preterm premature rupture of membranes. Cochrane Database of Systematic Reviews, 2:CD007062.

5. Nijman TA, van Vliet EO, Naaktgeboren CA, Oude Rengerink K, de Lange TS, Bax CJ, Bloemenkamp KW, van Eyck J, Kok M, Scheepers HC, Woiski M, Franx A, Mol BW and Oudijk MA. (2016): Nifedipine versus placebo in the treatment of preterm prelabor rupture of membranes: a randomized controlled trial: Assessment of perinatal outcome by use of tocolysis in early laborAPOSTEL IV trial. Eur J Obstet Gynecol Reprod Biol., 205:79-84.

6. Roos C, Spaanderman ME, Schuit E, Bloemenkamp KW, Bolte AC, Cornette J, Duvekot JJ and van Eyck J. (2013): Effect of maintenance tocolysis with nifedipine in threatened preterm labor on perinatal outcomes: A randomized controlled trial. JAMA, 309(1):41-7.

7. Ugwumadu A. (2011): Preterm prelabour rupture of membranes (pPROM). Best Practice in Labour and Delivery, 15: 23-29.

8. Weijerman ME, van Furth AM, Vonk Noordegraaf A, van Wouwe JP, Broers CJ and Gemke RJ. (2010): Prevalence, Neonatal Characteristics, and First-Year Mortality of Down syndrome: A National Study. J Pediatr., 152(1):15-9. 
تقدير نتائج ما بعد الو لادة عقب استخدام اقر اص النيفديبين

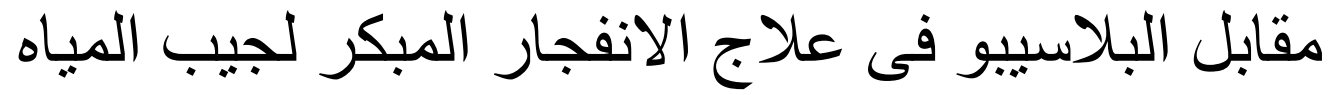
محمد جمال الدين أحمد الثنافعي، فريد إبراهيم حسن، مفيد فوزي محمد، داليا منير الايل

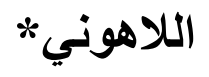

قسم النساء و التوليد، كلية الطب، جامعة الأزهر

*قمس الأطفال، كلية الطب، جامعة المنوفية

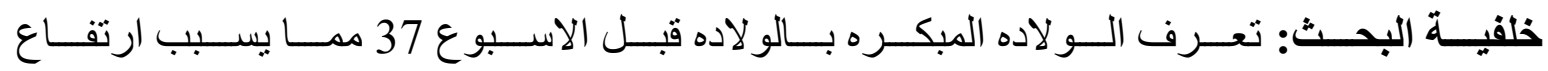

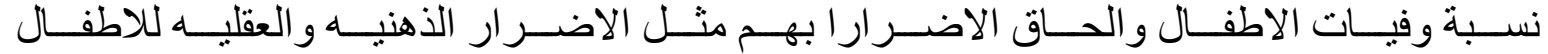

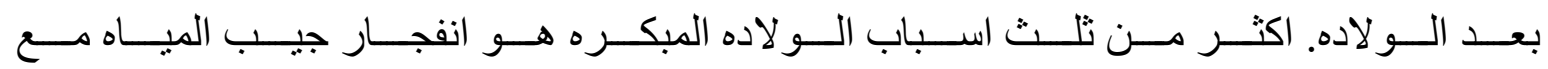

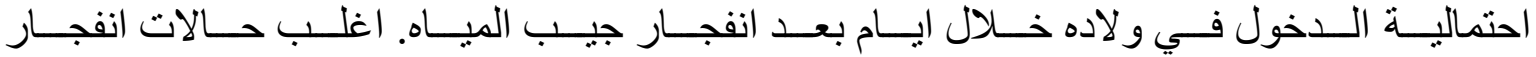

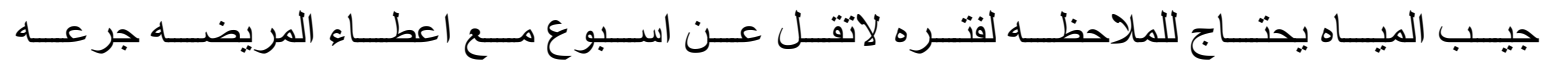

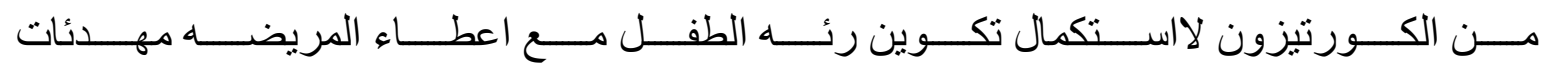

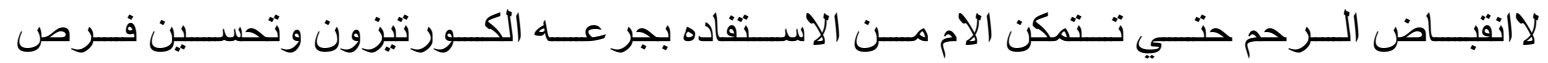

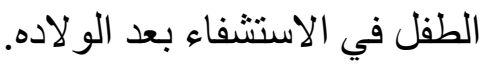

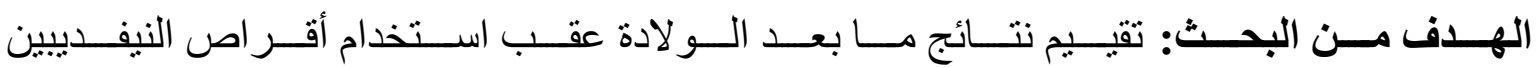
مقابل البلاسييو في علاج الانفجار المبكر لجيب اليباه.

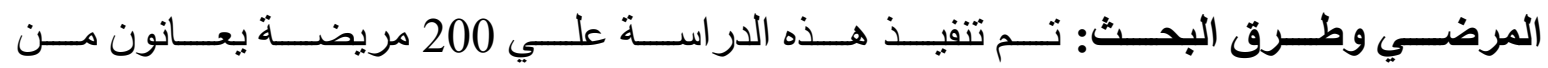

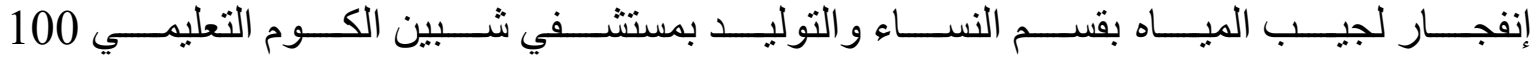

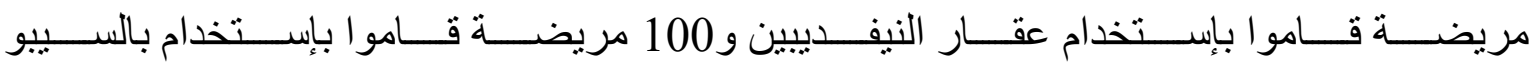

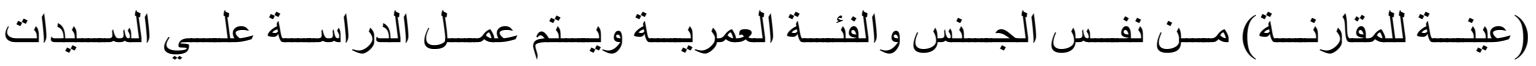

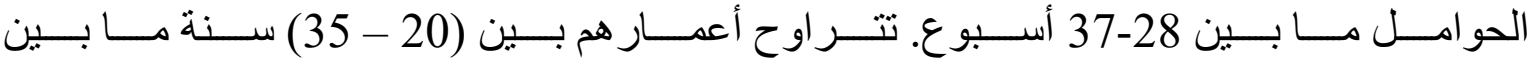

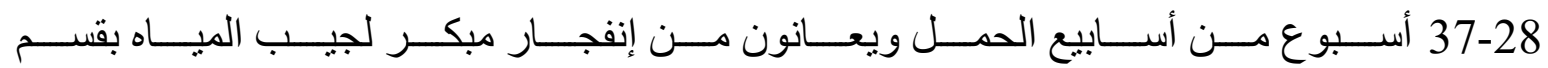

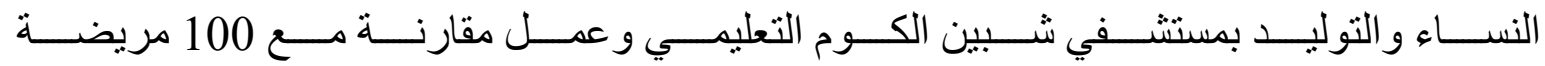

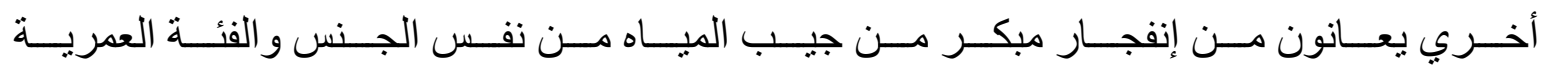
(عينة للمقارنة) من الفترة 2017 حتي 2019. 


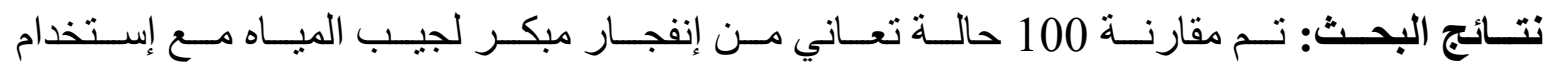

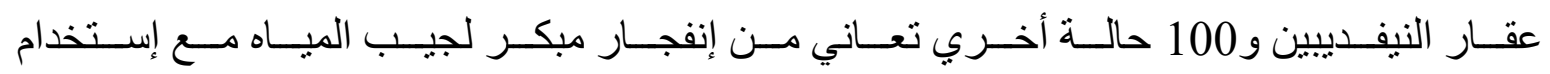

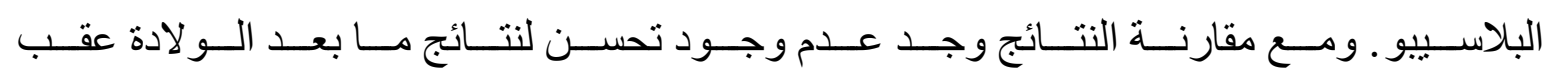
إستخدام اقر اص النيفديبين مقابل البلاسيبو في علاج الإنفجار المبكر لجيب المياه.

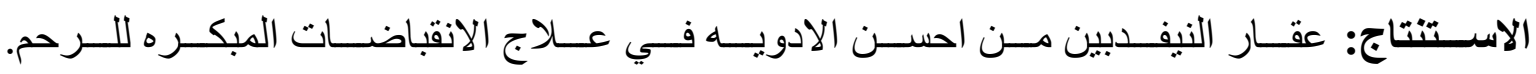

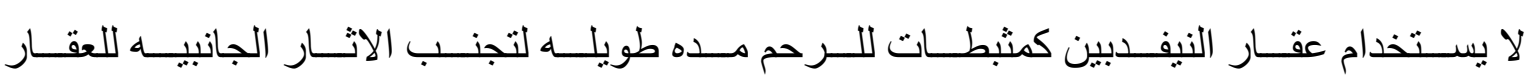
بل يستخدم لمده لاتتجاوز 48 ساعه لاعطاء جر عه الديكساميثازون.

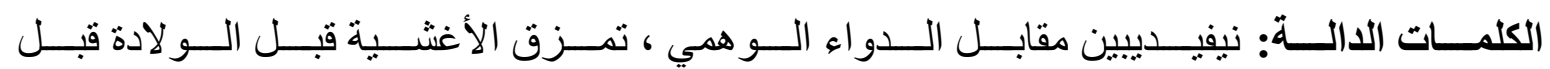
الأوان. 